\title{
INFLUENCE OF “COLD” DYEING TECHNOLOGY ON FABRIC CHARACTERISTICS
}

\author{
OLENA PAKHOLIUK, ${ }^{*}$ IRINA MARTIROSYAN, ${ }^{* *}$ VIRA LUBENETS $^{* * *}$ and \\ OKSANA PEREDRII* \\ "Lutsk National Technical University, 29 S. Kovalevska Ave., 43008 Lutsk, Ukraine \\ ** Odessa National Academy of Food Technologies, 112 Kanatna Str., 65039 Odessa, Ukraine \\ ${ }^{* * *}$ Lviv Polytechnic National University, 12 S. Bandery Str., 79013 Lviv, Ukraine \\ × Corresponding author: I. Martirosyan, miaviva@ukr.net
}

Received August 8, 2020

\begin{abstract}
The current work presents a comparative analysis of the colour fastness against repeated washing of cellulosecontaining fabrics dyed by "cold" and classical technologies, using different types of active dyes, at various concentrations in the dye bath. Mathematical models have been proposed to describe the determined dependencies. The study uses Reakol dyes - a trademark of bifunctional active dyes manufactured by Khimtex (Kherson), which can be used for "cold" resource-saving dying technologies. The studied active dyes are characterized by a wide colour spectrum, good solubility, colour purity and high resistance of colours to wet treatments.

The study has found that increasing the concentration of Reakol dyes in the dye bath, from 10 to $30 \mathrm{~g} / \mathrm{L}$, as a rule, had no significant influence on the colour fastness of fabrics to repeated washing. However, the colour intensity on the fibre significantly rose when increasing the dye concentration in the dye bath. It was determined that, when using the "cold" dyeing technology, sweeping changes in the general colour contrast and residual concentration of the dye on the fibre occurred after the first 5 washes. The changes in these indicators somewhat stabilized after the following 10-20 washes. However, a proportional relationship between the variation in the general colour contrast and a decrease in the dye colour intensity on the fibre after the corresponding number of washes of the studied fabrics was not detected.
\end{abstract}

Keywords: colour fastness to washing, general colour contrast, "cold” dyeing, Reakol, colour intensity

\section{INTRODUCTION}

The goal-oriented selection of dyes and dyeing technology that would guarantee not only the desired range of colours, but also more complete and effective use of the potential resource of the warp of fabrics, has a significant importance in ensuring uniform wear of the fibrous warp and colour of linen-containing textile materials. However, it should be emphasized that a limited number of works have been published to assess the role of basic, final and special treatments of linen-containing fabrics during wear after their wet cleaning. Therefore, in our studies on mixed linen-cotton fabrics intended for manufacturing dresses and shirts, the following tasks have been addressed: to study the dependence of colour fastness of the tested fabrics, under the effect of repeated washes, on the reactive dye used and its concentration in the dye bath; to make a comparative analysis of the colour fastness to washing of linen-cotton fabrics dyed with reactive dyes by the "cold" and classical dyeing technologies. ${ }^{1-4}$

Providing the desired colour fastness of textile fabrics to repeated washing has always been and remains relevant. Many researchers have devoted their work to solving this problem. Some authors have studied the role of fibrous composition and other structural parameters in the formation of colour fastness in textile materials under the action of washing, others focused their investigation on the effect of processing these materials on their colour fastness to wet treatments, and only a few researchers examined the influence of fibre structure and treatment methods of textile materials on their resistance to these factors. ${ }^{2-4}$ It is known that dyeing of flaxcontaining fabrics at an industrial scale is associated with significant consumption of heat and electricity. Therefore, it is of considerable interest to reduce the share of heat treatments or 
perform them at lower temperatures. Nowadays, this problem is especially relevant as most companies have difficulties with a stable supply of steam and electricity, which makes it impossible to maintain the temperature parameters of the dyeing process.

The roles of fibrous composition, structure and processing of textiles in the kinetics of their wear under the effect of repeated washes have been also examined by Xiao and Zhao, ${ }^{5}$ Rizk and Ibrahim, ${ }^{6}$ Pugachevsky, Semak, Halika, Cosmic and others. ${ }^{7-10}$ Still, the need to investigate the issues addressed in this work comes from the fact that in previous research publications on textile materials, the intensity of their wear taken as the frequency of washes is assessed, as a rule, separately, by examining the changes in the mechanical properties and colour fastness. However, it should be kept in mind that colour fastness generally decreases much faster than the mechanical properties of cellulose textile materials. ${ }^{11-16}$

\section{EXPERIMENTAL}

\section{Material}

The fabric used in the study was mixed linen and cotton material (linen weft and cotton warp). Its characteristics are presented in Table 1.

\section{Methods}

\section{Dyeing procedure}

The dyeing procedure was carried out in the laboratory of "DC Khimteks" (Kherson), according to two technologies: the "cold" resource-saving technology developed at "Khimteks", with a pad dyeing range for the concentration of each type of reactive dye (Reakol) in the dye bath, between 10 and $30 \mathrm{~g} / \mathrm{L}$; the traditional dyeing technology with a continuous pad-steam dyeing process, using the same types of dyes, but at the concentration of each dye in the dye bath of 2.0 and $3.0 \%$. The composition of the dyes is a trade secret.

The "cold" dyeing technology consisted of 3 stages: material preparation, dyeing and washing, as detailed below.

1. Material preparation: combining decoction and bleaching - for successful dyeing with reactive dyes, the preliminary preparation of the material is very important. The fabric was treated under the following conditions: Kolovet AN - 0.8-1.0 g/L, caustic soda $2.0 \mathrm{~g} / \mathrm{L}$; hydrogen peroxide - 2.0-4.0 g/L, peroxide stabilizer $-1.0 \mathrm{~g} / \mathrm{L}$, bath ratio of $1: 10$; temperature 98 ${ }^{\circ} \mathrm{C}$, time 45-60 min, which allowed achieving high purity and capillarity of the material for successful subsequent dyeing.

2. Dyeing was carried out under the following conditions: Reakol dye concentration (X\%) varied according to the desired colour (for deep black colour (Reakol black meta) - 6\%, for deep blue colour (Reakol sea blue) $-3 \%$, for other colours - between 0.3 and 3.0\%); leveller Cololevel $\mathrm{P}-0.5-1.0 \mathrm{~g} / \mathrm{L}$ (except for black); salt - Y g/L; caustic soda $-\mathrm{Z}$ g/L; bath ratio $-1: 10$, temperature $-60{ }^{\circ} \mathrm{C}$.

3 . Washing was performed in the following steps: 1) cold washing; 2) neutralization ( $0.5 \mathrm{~g} / \mathrm{L}$ acetic acid (50\%) at $40-50{ }^{\circ} \mathrm{C}$, for 5-10 min); 3) hot washing with a cleaning agent; 4) warm washing (Kolosoap A - 1.0 $\mathrm{g} / \mathrm{L}$, acetic acid - $1.0 \mathrm{~g} / \mathrm{L}$, time $-15 \mathrm{~min}$ ).

\section{Colour fastness investigation}

The colour fastness of the tested fabrics to repeated washes was determined by observing the variation of the indices of general colour contrast $(\Delta \mathrm{E})$ and colour intensity (values of function GKM, K/S) after 5, 10, 15 and 20 washes.

Spectral characteristics of the colours were obtained using a system of measurement and colour reproduction, which included: a Spectro Scan 5100 Spectrophotometer, a computer and a colour analysis software package. Colours were determined under standard emission (illuminant D65 and $10^{\circ}$ observer). Colour characteristics were calculated by the CIELab system.

Table 1

Characteristics of linen-cotton fabric intended for manufacturing dresses and shirts

\begin{tabular}{|c|c|c|c|c|c|c|}
\hline \multirow[t]{2}{*}{$\begin{array}{l}\text { Fibrous } \\
\text { composition, } \\
\%\end{array}$} & \multicolumn{2}{|c|}{$\begin{array}{c}\text { Linear density of } \\
\text { threads, } \mathrm{T}, \\
\text { tex }\end{array}$} & \multicolumn{2}{|c|}{$\begin{array}{c}\text { Density, } \mathrm{P}, \\
\text { number of threads } \\
\text { per } 100 \mathrm{~mm}\end{array}$} & \multirow[t]{2}{*}{$\begin{array}{l}\text { Surface } \\
\text { density, } \\
\mathrm{g} / \mathrm{m}^{2}\end{array}$} & \multirow[t]{2}{*}{$\begin{array}{c}\text { Cloth } \\
\text { structure }\end{array}$} \\
\hline & Warp & Weft & Warp & Weft & & \\
\hline $\begin{array}{l}\text { cotton }-44 \\
\text { linen }-56\end{array}$ & 29 & 50 & 240 & 165 & 160 & linen weave \\
\hline
\end{tabular}

For investigating colour fastness to washing, the fabrics were washed in a Bosch washing machine, using a solution of "Ocean" universal washing powder at a concentration of $5 \mathrm{~g} / \mathrm{L}$. The duration of one washing cycle was 30 minutes, at a temperature of the washing solution of $40^{\circ} \mathrm{C}$.

In order to eliminate the interfering effect of different dyes on the variation of colour fastness 
during washing, fabric samples dyed in different ways and using different types of dyes were washed separately. The total number of washes was 20, and the colour fastness was evaluated after every 5 washes. Each of the washing cycles corresponds to 6 household washes.

\section{RESULTS AND DISCUSSION}

The results of the evaluation of colour fastness to repeated washes on linen-cotton fabric dyed by the "cold" (samples 1-8) and classical (samples 912) technologies, using different Reakol dyes, at their respective concentrations in the dye baths, are shown in Table 2 and Figures 1 and 2.

As expected, it can be seen from the data presented in Table 2 and Figures 1 and 2 that the colour fastness on the tested fabrics, under the effect of repeated washes, depends not only on the type of the Reakol dye, its concentration in the dye bath and the method of dyeing, but also on the number of washes applied to the fabric. Thus, we will further define the role of these factors in the formation of colour fastness particularly.

It has been determined that more resistant colours to repeated washes are achieved after dyeing the fabric with Reakol red M. This is especially noticeable after the first 5 washing cycles.

Table 2

Variation of general colour contrast in linen-cotton fabrics after repeated washes

\begin{tabular}{clccccc}
\hline \multirow{2}{*}{$\begin{array}{c}\text { Fabric } \\
\text { sample } \\
\text { number }\end{array}$} & Dye type & $\begin{array}{c}\text { Concentration } \\
\text { of dye in dye } \\
\text { bath }\end{array}$ & \multicolumn{4}{c}{$\begin{array}{c}\text { General colour contrast }(\Delta \mathrm{E}) \text { after } \\
\text { repeated washes/ } \\
\text { Number of washes }\end{array}$} \\
\cline { 4 - 7 } & & "Cold" dyeing technology & 5 & 10 & 15 & 20 \\
\hline 1 & Reakol yellow (ZPL) & $10 \mathrm{~g} / \mathrm{L}$ & 5.8 & 8.7 & 9.6 & 10.7 \\
2 & Reakol turquoise & $10 \mathrm{~g} / \mathrm{L}$ & 4.6 & 4.7 & 4.8 & 4.9 \\
3 & Reakol blue R & $10 \mathrm{~g} / \mathrm{L}$ & 3.9 & 5.0 & 5.2 & 6.5 \\
4 & Reakol red M & $10 \mathrm{~g} / \mathrm{L}$ & 2.6 & 2.7 & 3.0 & 3.5 \\
5 & Reakol yellow (ZPL) & $30 \mathrm{~g} / \mathrm{L}$ & 9.9 & 12.6 & 12.8 & 14.2 \\
6 & Reakol turquoise & $30 \mathrm{~g} / \mathrm{L}$ & 4.4 & 4.6 & 4.9 & 5.0 \\
7 & Reakol blue R & $30 \mathrm{~g} / \mathrm{L}$ & 3.1 & 3.6 & 4.1 & 4.4 \\
8 & Reakol red M & $30 \mathrm{~g} / \mathrm{L}$ & 2.9 & 3.3 & 3.4 & 6.0 \\
\hline & & Classical dyeing technology & & & \\
\hline 9 & Reakol blue R & $2 \%$ & 1.6 & 3.8 & 4.1 & 4.5 \\
10 & Reakol turquoise & $2 \%$ & 2.4 & 2.7 & 3.1 & 3.9 \\
11 & Reakol yellow M & $3 \%$ & 2.3 & 5.9 & 6.0 & 6.4 \\
12 & Reakol red M & $3 \%$ & 1.0 & 2.5 & 2.8 & 4.0 \\
\hline
\end{tabular}

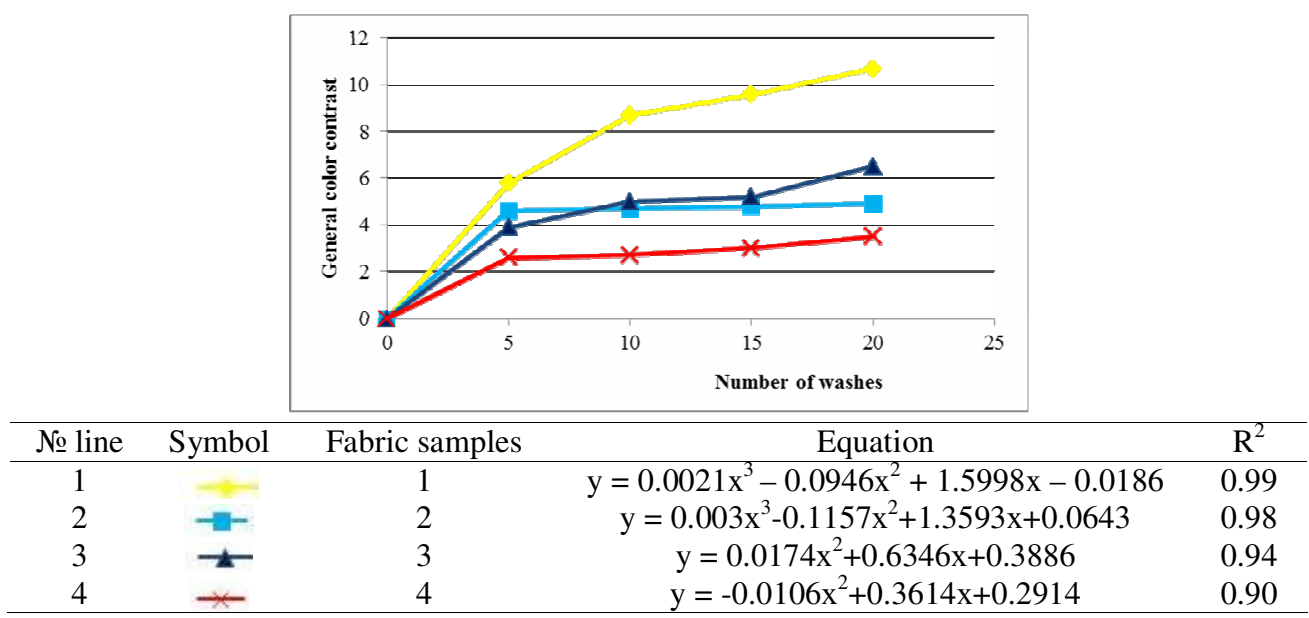

Figure 1: Effect of number of washing cycles on the evolution of general colour contrast in linen-cotton fabric dyed by the "cold" technology 


\section{OLENA PAKHOLIUK et al.}

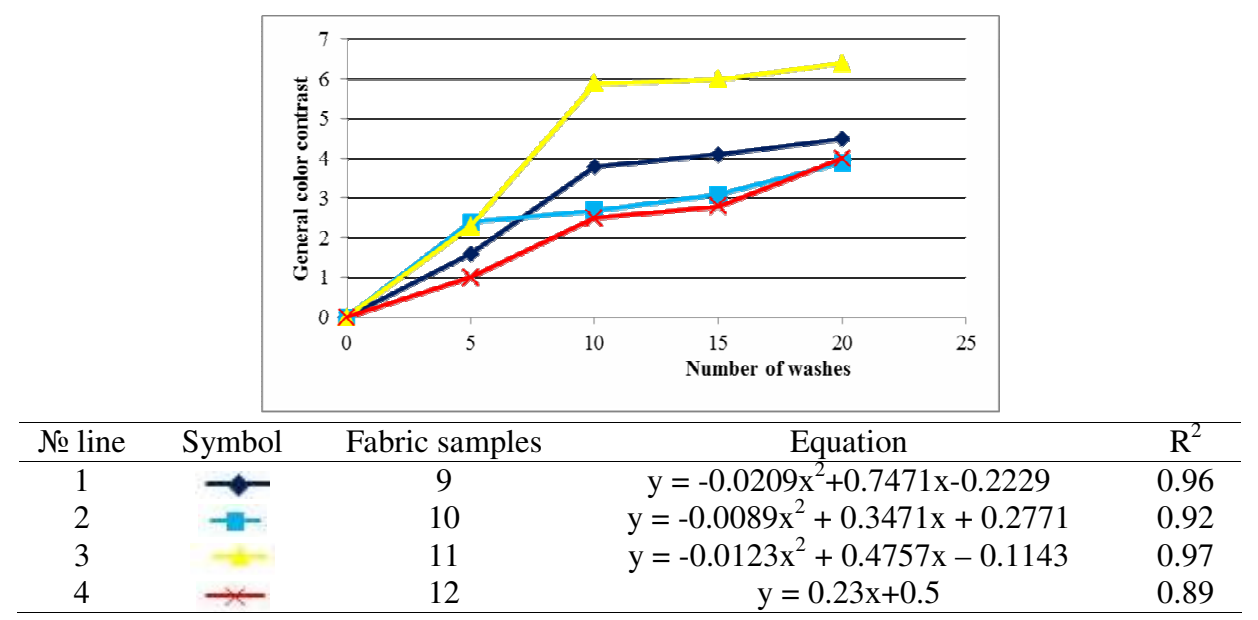

Figure 2: Effect of number of washing cycles on the evolution of general colour contrast in linen-cotton fabric dyed by the classical technology

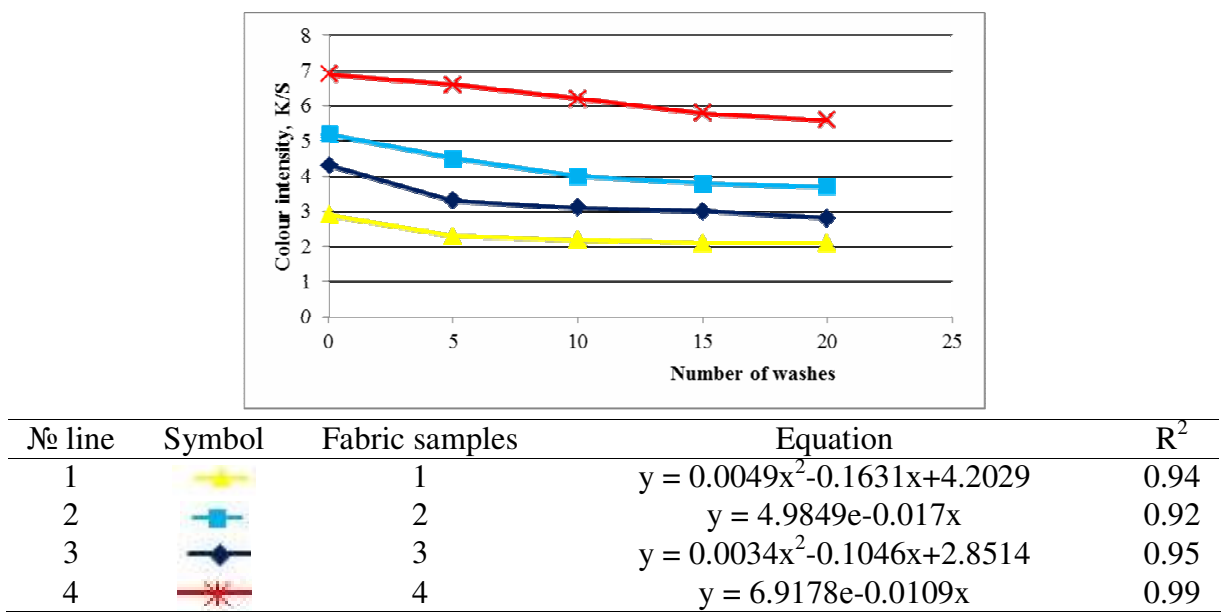

Figure 3: Impact of repeated washes on the evolution of colour intensity in linen-cotton fabric dyed by the "cold" technology

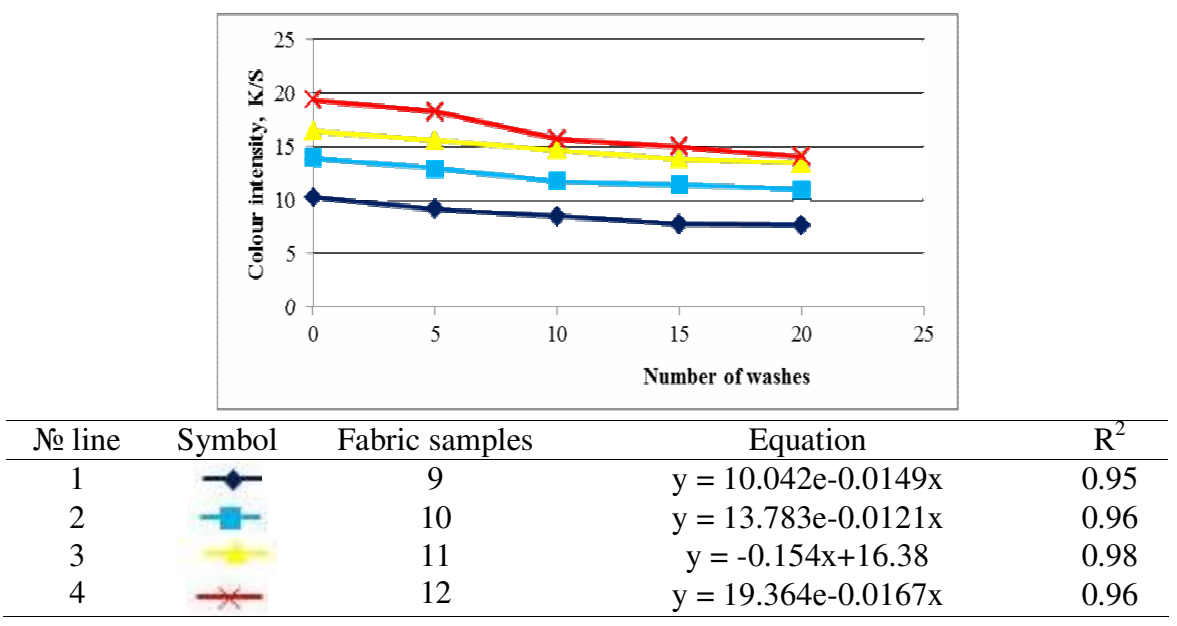

Figure 4: Impact of repeated washes on the evolution of colour intensity in linen-cotton fabric dyed by the classical technology 
Fabrics

Table 3

Colour intensity variation in linen-cotton fabric as a function of number of washes

\begin{tabular}{cccccc}
\hline Fabric sample & \multicolumn{5}{c}{ Values of GCM function, K/S (units), as a function of number of washes } \\
\cline { 2 - 6 } number & 0 & 5 & 10 & 15 & 20 \\
\hline 1 & 4.3 & 3.3 & 3.1 & 3.0 & 2.8 \\
2 & 5.2 & 4.5 & 4.0 & 3.8 & 3.7 \\
3 & 2.9 & 2.3 & 2.2 & 2.1 & 2.1 \\
4 & 6.9 & 6.6 & 6.2 & 5.8 & 5.6 \\
5 & 9.7 & 6.6 & 5.9 & 5.8 & 5.6 \\
6 & 11.0 & 10.9 & 10.3 & 9.5 & 8.6 \\
7 & 5.9 & 5.6 & 5.3 & 5.0 & 4.6 \\
8 & 14.9 & 13.8 & 12.6 & 11.8 & 9.9 \\
9 & 10.3 & 9.2 & 8.5 & 7.8 & 7.7 \\
10 & 14.0 & 13.0 & 11.8 & 11.5 & 11.0 \\
11 & 16.5 & 15.6 & 14.7 & 13.9 & 13.5 \\
12 & 19.4 & 18.3 & 15.7 & 15.0 & 14.1 \\
\hline
\end{tabular}

Thus, for example, the general colour contrast $(\Delta \mathrm{E})$ after 5 washes (each of which corresponds to 6 household washes) on the linen-cotton fabric dyed by Reakol yellow ZPL, Reakol turquoise, Reakol blue R and Reakol red M was 5.8, 4.6, 3.9 and 2.6, respectively.

It is important to emphasize the fact that the colour fastness to repeated washes has been observed to be determined mainly by the dye type rather than by the variation in colour intensity. Therefore, the residual concentration of the dyes on the linen-cotton fabric samples 1, 2, 3 and 4, after 20 washes, is $2.8 ; 3.7 ; 2.1$ and 5.6, respectively (Table 3, Figs. 3 and 4). The results of the investigation regarding the colour intensity variation for the different types of dyes used in the present study are shown in Table 3 .

The mathematical models presented in the form of polynomial equations in Figure 1 show that, in samples 1 and 2, there are 2 extrema (maximum values on the graph), which means that the number of washings affects fabrics differently, which can be explained by both the fibrous composition of the fabric and the dye used. In samples 3 and 4, the dye fastness to washing is retained only after 5 washes, i.e. even after one wash, the dye is better preserved in these samples. The symbol $\mathrm{Y}$ is the indicator of the general colour contrast, $\mathrm{X}^{3}$ is the maximum points that characterize the high resistance to the action of multiple washings - 15-20 in fabric samples 1 and $2 . X^{2}$ is the minimum point at which the indicator of the general colour contrast decreases after 5 washes in fabric samples 3 and 4 .

Figure 2 demonstrates the effect of repeated washes on the evolution of the general colour contrast in linen-cotton fabric, dyed by the classical technology. A higher colour contrast was achieved in fabric sample 1 after 10 washes, while the other samples had lower indicators of colour contrast under these conditions. The linear function of the dependence of colour retention on the fabric on the number of washes was determined for sample 4 .

$\mathrm{R}$ is the coefficient of determination, the maximum value of which is equal to 1 , showing the relationship between the studied indicators; the higher this coefficient, the more adequate the data obtained. In Figures 1-4, it can be noted that in all the situations investigated in the present work, this coefficient tends to 1 as much as possible. Thus, from these figures we can conclude that dyeing linen fabrics, which are normally poorly dyed because of their natural properties, using the "cold" technology allows achieving good results - fabrics maintain colour fastness after 20 washes - in comparison with the classical hot technology, where the colour contrast is lost after 5 washes.

As can be seen from the comparison of data in Tables 2 and 3, as well as in Figures 1-4, increasing the concentration of Reakol dyes in the dye bath from 10 to $30 \mathrm{~g} / \mathrm{L}$, as a rule, has no significant impact on the evolution of colour fastness under the effect of repeated washes. However, the colour intensity of the dyes on the fibres significantly rises when increasing their concentration in the dye bath. Thus, the optimal concentration of the investigated Reakol dyes, for dyeing linen-cotton fabrics intended for manufacturing dresses and shirts, was concluded to be $10 \mathrm{~g} / \mathrm{L}$ in the dye bath, using the "cold" dyeing technology. 
The influence of classical dyeing technology on the colour fastness of the fabrics under the influence of repeated washing has been studied on the example of dyes Reakol blue $\mathrm{R}$ and Reakol turquoise (at the concentration of $2 \%$ in the dye bath), as well as Reakol yellow M and Reakol red $\mathrm{M}$ (at the concentration of $3 \%$ in the dye bath). As can be seen from the analysis of the data in Table 2 and Figures 1-4, using the classical dyeing technology (fabric samples 9, 10, 11 and 12), generally, almost the same colour fastness to repeated washing is achieved. This leads to the conclusion that using the "cold" and classical technology of dyeing for linen-cotton fabrics leads to almost the same results in terms of the stability of the colours obtained.

However, it was also found that using the classical dyeing technology much more reactive dye is retained on the tested fabric (samples 9, 10, 11 and 12) than in the case of the "cold" technology. This difference, as can be seen from the data in Table 3, is maintained both before and after repeated washing. Thus, the data available on the changes in the colour intensity of the tested dyes on the fibre, after the respective number of washing cycles, do not allow drawing a clear conclusion about its direct impact on the colour fastness to washing.

Comparing the results obtained from the evaluation of colour fastness on the tested fabrics under the action of washing with the existing norms established by means of gray scale standards was considered to be appropriate. The minimum standards of colour fastness of especially strong, strong and ordinary colour, in light, medium and dark tones, on cellulosecontaining textile materials, under the influence of all types of wet treatments, are generally within 34 points on the gray scale. Considering the lower limit of the colour fastness of the tested fabrics, which is estimated by a contrast of 8 units $\Delta \mathrm{E}$ or 2 points on the gray scale, in this study, it was not reached even after 20 washes (which correspond to 120 household 5-minute washes).

The number of washing cycles has a certain effect on the evolution of the colour fastness to washing of the tested fabrics. In this case, the colour loss from fabrics in the process of washing was determined by two interrelated criteria - by an increase in the general colour contrast and by a reduction in the intensity of colour on the fibre, as a function of the number of washes. As can be seen from the analysis of the data in Table 1 and Table 2 and the curves in Figures 1 and 2, the evolution of the general colour contrast in the cold-dyed fabric as a result of repeated washes is described by virtually identical mathematical models - polynomial functions of different degrees. As for the decrease in the colour intensity of dyed fabric samples 1 and 2, and its dependence on the number of washes (Table 3, Figs. 3 and 4), under similar conditions, is described by a slightly different mathematical model (in most cases, an exponential function).

Simultaneously, the greatest changes in the parameters of general colour contrast and residual concentration of the dye on the fibre were observed when using the "cold" dyeing technology after the first 5 washes. The changes in these indicators stabilize somewhat after the following 10-20 washes. However, a proportional relationship between the changes in the general colour contrast and the decrease in the colour intensity of the dyes on the fibre after the corresponding number of washes of the studied fabrics (samples 1 and 2) was not detected. Similar relations in the behaviour of the indicators of the general colour contrast and residual concentration of dyes on the fibre, depending on the number of washes of the tested fabrics, were also found for fabrics dyed by the classical technology (samples 9, 10, 11 and 12) (Tables 13).

\section{CONCLUSION}

The findings of the study demonstrate that dyeing linen-cotton fabrics by the "cold" technology is a viable option, due to a number of advantages. The dyeing process is carried out at ambient temperature, without the use of heat. This technology involves less fabric preparation and does not require complex equipment. Consequently, this procedure uses lower amounts of water during processing and improves the working conditions. Moreover, it has been established that the "cold" technology of dyeing, in the case of the studied fabrics and dyes, allows obtaining similarly resistant dyeing to repeated washing as by the classical technology.

The results of the study have led to the following specific conclusions:

- Dyeing of linen-cotton fabrics with Reakol yellow ZPL, Reakol turquoise, Reakol blue R, Reakol red M and Reakol yellow $\mathrm{M}$ by both the "cold" and the classical technologies allows obtaining high colour fastness to repeated washing. 
- The use of the "cold" technology of dyeing for the investigated fabrics and the specific Reakol dyes used in the study led to the same colour fastness results to repeated washing as in the case of the classical dyeing technology. Also, the optimum concentration of these Reakol dyes in the dye bath was found to be $10 \mathrm{~g} / \mathrm{L}$ utilizing the "cold" technology.

- Mathematical models have been proposed to describe the dependence of colour fastness to repeated washing on the tested fabrics on the reactive dye type, its concentration in the dye solution and on the fibre, the method of dyeing and the number of washes. However, no proportional relationship between the increase in the general colour contrast as a result of repeated washing of the tested fabrics and the evolution of colour intensity after the corresponding number of washes was detected.

- The use of the "cold" resource-saving technology for dyeing cellulose-containing textile materials, including flax-containing materials, allows solving a number of problems, namely: to preserve the valuable mechanical and antibacterial properties of flax fibre and offer them to the consumer (when using the traditional dyeing technology, these properties are significantly lost); to reduce to a great extent the consumption of electricity, steam, water and chemicals; to increase the light fastness of colours by appropriate selection of individual type of reactive dyes and their concentrations (in the dye bath and on the fibre); to increase significantly the competitiveness of domestic flax-containing fabrics on domestic and foreign markets.

\section{REFERENCES}

1 N. Singh and O. Sahu, in "The Impact and Prospects of Green Chemistry for Textile Technology", The Textile Institute Book Series, edited by S. Islam and B. S. Butola, 2019, https://doi.org/10.1016/B978-0-08-102491-1.00004-6

2 S. Adeel, F. Rehman, T. Gulzar and I. Bhatti, Chem. Asian J., 25, $2739 \quad$ (2013), http://dx.doi.org/10.14233/ajchem.2013.13765

3 M. Ajmal, S. Adeel, M. Azeem, M. Zuber, N. Akhtar et al., Ind. Crop. Prod., 58, 188 (2014), https://doi.org/10.1016/j.indcrop.2014.04.026

4 I. Perelshtein, N. Perkas and A. Gedanken, in "The Impact and Prospects of Green Chemistry for Textile Technology", The Textile Institute Book Series, edited by S. Islam and B. S. Butola, 2019, pp. 161-198, https://doi.org/10.1016/B978-0-08-102491-1.00007-1
5 H. Xiao, T. Zhao, C.-H. Li and M.-Y. Li, J. Clean. Prod., 165, 1499 (2017), https://doi.org/10.1016/j.jclepro.2017.07.174

6 H. F. Rizk, S. A. Ibrahim and M. A. El-Borai, Dyes Pigments, 112, $86 \quad$ (2015), https://doi.org/10.1016/j.dyepig.2014.06.026

7 D. Shu, K. Fang, X. Liu, Y. Cai, F. An et al., J. Clean. Prod., 241, $118370 \quad$ (2019), https://doi.org/10.1016/j.jclepro.2019.118370

8 M. Sohaib Atiq, A. Rehman, K. Iqbal, F. Safdar, A. Basit et al., Cellulose Chem. Technol., 53, 155 (2019), https://doi.org/10.35812/CelluloseChemTechnol.2019. 53.17

9 N. Muhammed and N. Govindan, Cellulose Chem. Technol., $\quad 54, \quad 553 \quad$ (2020), https://doi.org/10.35812/CelluloseChemTechnol.2020. 54.56

10 U. Habibah Siddiqua, S. Ali, M. Iqbal and T. Hussain, J. Mol. Liquids, 241, 839 (2017), https://doi.org/10.1016/j.molliq.2017.04.057

11 I. S. Galik and D. B. Semak, Herald of Khmelnytskyi National University, 6, 219 (2014)

12 E. Pakholiuk, I. Martirosyan, V. Lubenets and O. Peredriy, Techn. Complex. Sci. J., 1, 52 (2018)

13 O. Pakholiuk, in Procs. Commodity Science and Trade Entrepreneurship: Professional Professionalization, Research, Innovation Symposium, Kyiv, April 15-16, 2009, pp. 202-204

14 I. Martirosyan, O. Pakholiuk, B. Semak, V. Lubenets and O. Peredriy, in: "Advanced Manufacturing Processes", Lecture Notes in Mechanical Engineering Book Series, edited by V. Tonkonogyi et al., Springer, 2020, p. 433, https://doi.org/10.1007/978-3-030-40724-7_44

15 A. Hadj Taieb, M. Ben Amor, D. Maroini and S. Msahli, IJESRT, 5, 278 (2016)

16 A. A. Khan, N. Iqbal, S. Adeel, M. Azeem, F. Batool et al., Dyes Pigm., 103, 50 (2014) 